\title{
Insight in bipolar disorder: a comparison between mania, depression and euthymia using the Insight Scale for Affective Disorders
}

\author{
O insight no transtorno bipolar: uma comparação entre mania, depressão e \\ eutimia usando a Escala de Insight para Transtornos Afetivos
}

\begin{abstract}
Rafael de Assis da Silva, ${ }^{1,2}$ Daniel C. Mograbi, ${ }^{3,4}$ Evelyn V. M. Camelo, ${ }^{2}$ Jaqueline Bifano, ${ }^{2}$ Mayra Wainstok, ${ }^{2}$ Luciana Angélica Silva Silveira, ${ }^{2}$ Elie Cheniaux ${ }^{2,5}$
\end{abstract}

\begin{abstract}
Objective: To evaluate whether having general insight into bipolar disorder and its symptoms is affected by the mood state of the patient, using the Insight Scale for Affective Disorders, a hetero-application scale for people with mood disorders.

Methods: Ninety-five patients with bipolar disorder were evaluated and divided into different groups according to the mood state presented during assessment (i.e., euthymia, mania and depression). Sociodemographic and clinical data (Hamilton Depression Scale, Young Mania Rating Scale, and Clinical Global Impressions Scale) were recorded. Insight was evaluated using the Insight Scale for Affective Disorders.

Results: Patients with bipolar disorder in mania show less insight about their condition than patients in depression or euthymia, and less insight about their symptoms than patients with depression, with the exception of awareness of weight change.

Conclusions: Loss of insight during mania may have important implications for treatment compliance and adherence and needs to be taken into account in the clinical management of people with bipolar disorder.

Keywords: Insight, awareness, bipolar disorder, mania, anosognosia.
\end{abstract}

\section{Resumo}

Objetivo: Avaliar se o insight global sobre transtorno bipolar e sobre seus sintomas é afetado pelo estado de humor do paciente, usando a Escala de Insight para Transtornos Afetivos, uma escala de heteroaplicação para pacientes com transtorno do humor. Métodos: Noventa e cinco pacientes com transtorno bipolar foram avaliados e divididos em diferentes grupos de acordo com o estado de humor presente durante a avaliação (i.e., eutimia, mania e depressão). Dados sociodemográficos e clínicos (Escala de Depressão de Hamilton, Escala de Avaliação de Mania de Young e Escala de Impressão Clínica Global) foram registrados. O insight foi avaliado usando a Escala de Insight para Transtornos Afetivos. Resultados: Pacientes bipolares em mania apresentaram menor insight sobre sua condição do que pacientes em depressão ou eutimia, e menor insight sobre seus sintomas do que pacientes em depressão, exceto para consciência de mudança de peso. Conclusões: A perda de insight durante a mania pode ter importantes implicações para aceitação do e aderência ao tratamento e precisa ser levada em conta no manejo clínico de pacientes bipolares.

Descritores: Insight, consciência de morbidade, transtorno bipolar, mania, anosognosia.

\footnotetext{
${ }^{1}$ Universidade Federal do Estado do Rio de Janeiro (UNIRIO), Rio de Janeiro, RJ, Brazil. ${ }^{2}$ Instituto de Psiquiatria (IPUB), Universidade Federal do Rio de Janeiro (UFRJ), Rio de Janeiro, RJ, Brazil. ${ }^{3}$ Pontifícia Universidade Católica do Rio de Janeiro (PUC-Rio), Rio de Janeiro, RJ, Brazil. ${ }^{4}$ Institute of Psychiatry, King's College London, London, UK. ${ }^{5}$ Faculdade de Ciências Médicas (FCM), Universidade do Estado do Rio de Janeiro (UERJ), Rio de Janeiro, RJ, Brazil. Financial support: none.

Submitted Mar 13 2015, accepted for publication Jun 29 2015. No conflicts of interest declared concerning the publication of this article.

Suggested citation: de Assis da Silva R, Mograbi DC, Camelo EV, Bifano J, Wainstok M, Silveira LAS, et al. Insight in bipolar disorder: a comparison between mania, depression and euthymia using the Insight Scale for Affective Disorders. Trends Psychiatry Psychother. 2015;37(3):152-156. http://dx.doi.org/10.1590/22376089-2015-0014
} 


\section{Introduction}

Studies about insight have shown that this is a multidimensional and complex phenomenon. ${ }^{1}$ Dimensions include, for example, insight about the illness, about the need for treatment, and about the consequences associated with the illness. Initially, most studies about insight were conducted with patients suffering from schizophrenia. ${ }^{2}$ However, in the last few years, there has been an increase in interest about insight in patients with bipolar disorder (BD). ${ }^{3}$ A large proportion of patients studied have shown a lack of awareness about being ill or a poor understanding of the specific signs and symptoms associated with the condition. ${ }^{4}$ The degree of awareness about having a disorder or about its symptoms or even about the psychosocial negative consequences of such illnesses may significantly influence the course of these disorders. ${ }^{3}$ For instance, insight may have an effect on the patient's adherence to prescribed treatments. ${ }^{5}$

Many studies have been published on insight into behavioral disorders, with a wide spectrum of assessment methods being used to evaluate insight. Some studies 6,7 used specific items of clinical scales, e.g., the Young Mania Rating Scale (YMRS) ${ }^{8}$ or the Hamilton Depression Scale (HAM-D). ${ }^{9}$ Other studies ${ }^{2,10-12}$ used instruments designed to evaluate insight into psychosis, e.g., the Scale to Assess Unawareness of Mental Disorder (SUMD) ${ }^{1}$ and the Schedule for Assessment of Insight. ${ }^{13}$ However, those instruments were only validated for patients with non-affective psychotic disorders, and for this reason do not effectively measure the symptomatology or clinical course of mood disorders.

Some scales for assessing insight specifically into mood disorders were created, e.g., the Mood Disorder Insight Scale ${ }^{14}$ and the Beck Cognitive Insight Scale. ${ }^{15}$ Both are self-evaluation scales that can be used with patients with mood disorders. However, evaluation of insight through the use of self-evaluation instruments may result in discrepancies when compared with objective evaluations. ${ }^{16,17}$ In light of these different measurement tools, Olaya et al. ${ }^{18}$ developed the Insight Scale for Affective Disorders (ISAD), which relies on hetero-application for patients with mood disorders.

The objective of our study was to evaluate whether having general insight into $\mathrm{BD}$ and its symptoms is affected by the clinical state of a patient. For this purpose, we compared three groups of patients with BD in different phases: mania, depression and euthymia. We also used an evaluation scale on insight specifically geared towards mood disorders. To the best of our knowledge, there have been no other studies that have evaluated insight for bipolar patients (in different phases of the illness) using a hetero-evaluation scale specifically designed for patients with mood disorders.

\section{Material and methods}

\section{Participants}

The study was performed between November 2013 and November 2014 in an outpatient clinic at the Institute of Psychiatry, Universidade Federal do Rio de Janeiro (UFRJ), Rio de Janeiro, Brazil. During this period, all patients referred to the service were consecutively assessed and received a psychiatric diagnosis. The evaluations were conducted by researchers at the clinic. All researchers are doctors who have been trained to apply the instruments employed. In order to take part in the study, the patients needed to have had a diagnosis of type 1 or 2 BD, been aged 18 or over, and signed a free informed consent form. The study was approved by the local Research Ethics Committee.

\section{Clinical evaluation}

The identification and socioeconomic data of all patients were recorded. Psychiatric diagnoses were based on criteria from the Diagnostic and Statistical Manual of Mental Disorders, 5th edition (DSM-5) ${ }^{19}$ and established through clinical evaluation.

At each consultation, the affective state of each patient was evaluated using DSM-5 criteria for manic and depressive episodes. For the purpose of this study, patients with mixed episodes were excluded. In parallel, the following measurement scales were used: the HAM-D, ${ }^{9}$ YMRS, $^{8}$ and Clinical Global Impressions Scale for Use in Bipolar Illness (CGI-BP). ${ }^{20}$ The HAM-D is composed of 17 items that assess depressive symptoms. The YMRS is composed of 11 items that assess manic symptoms. The CGI-BP presents a global score relative to the severity of the affective episode.

Patients were evaluated using the hetero-evaluation questionnaire ISAD, which was developed by Olaya et al. ${ }^{18}$ and was translated into Portuguese and adapted for use in Brazil by Silva et al. ${ }^{21}$ This instrument, which was designed based on the SUMD, ${ }^{2}$ is a multidimensional assessment composed of 17 items. Each question is scored from 0 to 5 , where 0 represents the absence of symptoms or a situation where this cannot be evaluated; 1 constitutes full awareness of psychiatric morbidity; 3 represents a moderate awareness of psychiatric morbidity; and 5 constitutes the absence of awareness of psychiatric morbidity.

The main analysis of our study involved the investigation of insight in different affective states. 
With this goal in mind, patients were divided into three groups: euthymia, mania and depression. Patients were consecutively assessed at the clinic, and each patient was assigned to a just one group, based on their mood state at the time of assessment. The testing continued until a minimum of 30 patients per group was reached.

\section{Data analysis}

Descriptive statistics were used to analyze the demographic and clinical characteristics of the sample. For age, YMRS, HAM-D, and CGI scores, patient groups were compared using one-way analysis of variance (ANOVA), followed by post-hoc $t$ tests adjusted with Bonferroni corrections. To explore differences in gender distribution, a chi-square test was used.

For items \# 1 to \# 3 of the ISAD, measuring insight of the overall condition and having a disorder, patients in the three states (euthymia, depression and mania) were compared using one-way ANOVA, followed by post-hoc Bonferronicorrected $t$ tests. For items \#4 to \#17, measuring insight of specific symptoms, patients in euthymia were excluded from the analysis because they did not present symptoms. In this case, $t$ tests were used to compare patients in depression and in mania; for each variable, only patients who presented the symptom were included.

\section{Results}

\section{Sample characteristics}

The final sample included 95 patients with type $1 \mathrm{BD}$. None of the patients were diagnosed as having type $2 \mathrm{BD}$. Of the 95 patients, 32 were suffering from mania, 30 from depression and 33 from euthymia. In terms of gender distribution, the sample comprised 61 women and 34 men. Mean age was $47.3 \pm 11.6$ years. Sociodemographic and clinical characteristics of the sample are described in Table 1 . There were no differences between groups in terms of age $\left(F_{2,92}=\right.$ $0.63, p=0.534)$ or gender distribution $\left(X^{2}{ }_{[2]}=1.39\right.$, $p=0.498)$. There were significant differences in YMRS $\left(F_{2,92}=165.00, p<0.001\right)$ and HAM-D scores $\left(F_{2,92}=\right.$ $100.33, p<0.001)$. Patients in mania had higher YMRS scores than patients in the other states $(p<0.001)$. Similarly, patients in depression had higher HAM-D scores in comparison to the other patients $(p<0.001)$. Finally, there were differences in symptom severity $\left(F_{2,92}\right.$ $=140.24, \mathrm{p}<0.001$ ), with patients in euthymia having lower scores than patients in mania or depression $(p<$ 0.001 ), but without differences between the latter two groups $(p=0.462)$.

Table 1 - Sociodemographic and clinical characteristics of participants

\begin{tabular}{lcccc}
\hline Variable & Euthymia $(\mathbf{n}=\mathbf{3 3})$ & Mania $(\mathbf{n}=\mathbf{3 2})$ & Depression $(\mathbf{n}=\mathbf{3 0})$ & Group differences \\
\hline Age & $46.9 \pm 11.4(23-70)$ & $46.0 \pm 11.0(26-66)$ & $49.2 \pm 12.5(28-78)$ & - \\
Gender (female/male) & $23 / 10$ & $18 / 14$ & $20 / 10$ & - \\
YMRS & $1.4 \pm 2.1(0-7)$ & $24.3 \pm 9.1(9-41)$ & $3.1 \pm 2.8(0-10)$ & $M>D=E$ \\
HAM-D & $2.8 \pm 2.6(0-10)$ & $3.5 \pm 2.6(0-10)$ & $16.1 \pm 6.3(2-28)$ & $D>M=E$ \\
CGI global & $1.2 \pm 0.4(1-2)$ & $4.8 \pm 1.2(3-7)$ & $4.5 \pm 1.0(3-6)$ & $M=D>E$ \\
\hline
\end{tabular}

Data presented as mean \pm standard deviation (range), unless otherwise stated.

Group differences tested with a $X^{2}$ test. Differences in all other variables explored with analysis of variance (ANOVA) followed by pairwise $t$ tests.

CGI = Clinical Global Impression scale; HAM-D = Hamilton Depression Rating Scale; YMRS = Young Mania Rating Scale.

\section{Insight about condition}

Mean scores for ISAD items \#1, \#2, and \#3 can be found in Table 2. There were significant differences between the patient groups for all three items (item $\# 1: F_{2,92}=17.55, p<0.001$; item $\# 2: F_{2,92}=10.07$, $p<0.001$; item \#3: $\left.F_{2,92}=13.53, p<0.001\right)$. In all cases, post-hoc pairwise comparisons indicated poorer insight in patients in mania compared with patients in depression or euthymia ( $p<0.006$ ), with no significant differences between depression and euthymia ( $p>0.05)$.

Table 2 - Insight about condition in bipolar disorder patients in euthymia, mania and depression

\begin{tabular}{|c|c|c|c|c|}
\hline Variable & $\begin{array}{c}\text { Euthymia } \\
(n=33)\end{array}$ & $\begin{array}{c}\text { Mania } \\
(n=32)\end{array}$ & $\begin{array}{c}\text { Depression } \\
(\mathbf{n}=\mathbf{3 0})\end{array}$ & $\begin{array}{c}\text { Group } \\
\text { differences }\end{array}$ \\
\hline \#1 Awareness of suffering from an affective disorder & $1.7 \pm 1.1$ & $3.4 \pm 1.5$ & $1.7 \pm 1.3$ & $M>D=E$ \\
\hline $\begin{array}{l}\text { \#2 Awareness of treatment efficacy for current } \\
\text { symptoms or preventing relapses }\end{array}$ & $1.3 \pm 0.8$ & $2.4 \pm 1.4$ & $1.5 \pm 1.0$ & $M>D=E$ \\
\hline $\begin{array}{l}\text { \#3 Awareness of consequences of the illness on work, } \\
\text { family and social life }\end{array}$ & $1.6 \pm 1.2$ & $3.2 \pm 1.8$ & $1.5 \pm 1.2$ & $M>D=E$ \\
\hline
\end{tabular}

Data presented as mean \pm standard deviation. 


\section{Insight about symptoms}

Mean scores for ISAD items \#4 to \#16 are shown in Table 3. With the exception of item \#6 (Awareness of suffering a significant increase/loss of weight), patients in mania showed worse insight about symptoms compared to patients in depression (all $p<0.05$ ). Because few patients exhibited disorientation (\#15) and delusions/ hallucinations (\#17) (five and 17 patients, respectively), these items were not included in the analysis.

Table 3 - Insight about symptoms in bipolar disorder patients in mania and depression

\begin{tabular}{|c|c|c|c|}
\hline Items & $\begin{array}{c}\text { Mania } \\
(n=32)\end{array}$ & $\begin{array}{c}\text { Depression } \\
(n=30)\end{array}$ & p-value \\
\hline \#4 Awareness of suffering from a depressed/expansive or irritable mood $(\mathrm{mv}=1)$ & $3.6 \pm 1.5$ & $1.4 \pm 1.1$ & $<0.001$ \\
\hline \#5 Awareness of suffering a marked increase/reduction in pleasurable activities ( $\mathrm{mv}=13$ ) & $2.3 \pm 1.4$ & $1.4 \pm 1.1$ & 0.009 \\
\hline \#6 Awareness of suffering a significant increase/loss of weight $(\mathrm{mv}=36)$ & $1.7 \pm 1.3$ & $1.1 \pm 0.3$ & 0.056 \\
\hline \#7 Awareness of suffering from insomnia or hypersomnia $(m v=21)$ & $2.5 \pm 1.6$ & $1.5 \pm 1.1$ & 0.010 \\
\hline \#8 Awareness of suffering from sluggishness or psychomotor agitation $(m v=14)$ & $4.0 \pm 1.4$ & $1.5 \pm 1.3$ & $<0.001$ \\
\hline \#9 Awareness of suffering from fatigue or an excess of energy $(m v=8)$ & $3.5 \pm 1.7$ & $1.2 \pm 0.5$ & $<0.001$ \\
\hline \#10 Awareness of suffering from feelings of uselessness/guilt or grandiosity ( $m v=25$ ) & $3.5 \pm 1.5$ & $1.9 \pm 1.4$ & $<0.001$ \\
\hline \#11 Awareness of suffering from slowed speech or verbosity / garrulousness ( $m v=20$ ) & $3.6 \pm 1.5$ & $1.5 \pm 1.0$ & $<0.001$ \\
\hline \#12 Awareness of suffering from bradypsychia/idea flight $(\mathrm{mv}=28)$ & $3.8 \pm 1.5$ & $1.9 \pm 1.2$ & $<0.001$ \\
\hline \#13 Awareness of having a short attention span/showing distractibility $(\mathrm{mv}=21)$ & $3.7 \pm 1.6$ & $1.7 \pm 1.3$ & $<0.001$ \\
\hline \#14 Awareness of having an untidy appearance $(\mathrm{mv}=32)$ & $3.1 \pm 1.6$ & $1.7 \pm 1.3$ & 0.011 \\
\hline$\# 16$ Awareness of having poor social relationships $(\mathrm{mv}=17)$ & $2.5 \pm 1.5$ & $1.4 \pm 1.1$ & 0.003 \\
\hline
\end{tabular}

Data presented as mean \pm standard deviation.

$\mathrm{mv}=$ missing values.

\section{Discussion}

The findings of this study suggest that, during mania, patients with BD show greater impairment of insight than during depression or euthymia. The first three items of the scale were evaluated in all participants (awareness of having BD, awareness of the effectiveness of treatment for the actual symptoms or to prevent a reoccurrence of the illness, and awareness of the consequences of the disorder on their work, family, and social life). In the comparison between groups, individuals with mania showed less insight than those in the depression phase or in euthymia. These findings are consistent with other studies showing that individuals suffering from mania exhibit less insight about the effectiveness of treatment and the social consequences of the disorder in comparison to those with depression or euthymia. ${ }^{11,22,23}$ Also in relation to the first three items, the present study did not find any differences between depression and euthymia. In past studies, the preservation of insight in the depressive phase of BD has also been observed. ${ }^{7,16,17}$

The development of the ISAD was based on the SUMD. ${ }^{1}$ The SUMD, in turn, was developed to be applied in studies involving patients with schizophrenia and contained the first three ISAD items. Several studies have compared patients with schizophrenia and those with BD utilizing different insight evaluation methods, including the SUMD. ${ }^{3}$ A large proportion of such studies reported higher levels of insight in patients with BD compared with those with schizophrenia in at least one of the three evaluation items (i.e., global insight or awareness of the illness, awareness of treatment, or possible social consequences). ${ }^{4,24}$ It is possible that a greater frequency of psychotic symptoms, greater cognitive impairment and a more deteriorating course of the illness in schizophrenia ${ }^{25}$ when compared to $\mathrm{BD}$ may be responsible for the greater insight impairment reported in association with schizophrenia.

In our study, some patients with euthymia exhibited impairments of insight. This suggests that there are other factors besides the affective state that may influence psychiatric morbidity awareness in patients with BD. In this case, cognitive deficits may be related to high levels of insight impairment. ${ }^{26}$ Low levels of insight were associated with poor performance in tests of executive function, ${ }^{12,27}$ divided attention, cognitive flexibility, working memory, response inhibition, and interference resolution, all of which are mediated by the frontal lobes. In addition, deficits in verbal fluency were significantly associated with high levels of insight impairment. ${ }^{27}$ These results reinforce the notion that insight is a neurocognitive capacity, associated with prefrontal and frontoparietal dysfunction in patients with $\mathrm{BD}$ and low levels of insight. ${ }^{27}$

Our study showed that, in relation to all symptoms except weight loss, patients with mania had lower 
insight levels than those with depression. These findings reinforce the idea that patients with mania have greater difficulty in being aware of their symptoms than patients with depression. The current study has an advantage over previous studies in that it investigated insight using a specific scale tailored to mood disorders (ISAD). Using this scale allowed us to conduct a detailed evaluation of insight into specific symptoms of mood disorder.

A limitation of this study concerns the use of a between-subjects design, with comparisons between affective states being made with different individuals. A within-subjects design would have been more appropriate, allowing for each patient to be their own control. Nevertheless, this was not possible due to recruitment constraints: sampling of patients who have been across all three different mood states would take a considerably longer time. Another limitation of this study is the fact that clinical characteristics that could potentially influence insight, e.g., number of previous episodes or duration of illness, were not evaluated.

\section{Conclusions}

Patients with BD in mania have less insight about their condition and about their symptoms than patients with $\mathrm{BD}$ in depression or euthymia. Considering the pervasive role of insight in treatment compliance and adherence, clinical management of BD should take into account the level of awareness of patients. For instance, use of selfreported information should be avoided with patients in mania, with cross-validation of data with informants being used whenever possible. Additionally, assessment of risk, including functional capacity, should consider the issue of loss of insight. Finally, attempts to improve use of medication should be made with this population, considering their impaired awareness about the condition.

\section{References}

1. Amador XF, Strauss DH, Yale SA, Flaum MM, Endicott J, Gorman JM. Assessment of insight in psychosis. Am J Psychiatry. 1993;150:873-9.

2. Amador XF, Flaum M, Andreasen NC, Strauss DH, Yale SA, Clark $\mathrm{SC}$, et al. Awareness of illness in schizophrenia and schizoaffective and mood disorders. Arch Gen Psychiatry. 1994;51:826-36.

3. Silva RA, Mograbi DC, Landeira-Fernades J, Cheniaux E. O insight no transtorno bipolar: uma revisão sistemática. J Bras Psiquiatr. 2014;63:242-54.

4. Pini S, Cassano GB, Dell'Osso L, Amador XF. Insight into illness in schizophrenia, schizoaffective and mood disorders with psychotic features. Am J Psychiatry. 2001;158:122-5.

5. Yen CF, Chen CS, Ko CH, Yeh ML, Yang SJ, Yen JY, et al. Relationships between insight and medication adherence in outpatients with schizophrenia and bipolar disorder: prospective study. Psychiatry Clin Neurosci. 2005;59:403-9.

6. Cassidy F. Insight in bipolar disorder: relationship to episode subtypes and symptom dimensions. Neuropsychiatr Dis Treat. 2010;6:627-31.
7. de Assis da Silva R, Mograbi DC, Silveira LA, Nunes AL, Novis FD, Landeira-Fernandez $\mathrm{J}$, et al. Insight across the different mood states of bipolar disorder. Psychiatr Q. 2015;86:395-405.

8. Young RC, Biggs JT, Ziegler VE, Meyer DA. A rating scale for mania: reliability, validity and sensitivity. Br J Psychiatry. 1978;133:429-35.

9. Hamilton M. A rating scale for depression. J Neurol Neurosurg Psychiatry. 1960;23:56-62.

10. Cassidy F, Murry E, Forest K, Carroll BJ. Signs and symptoms of mania in pure and mixed episodes. J Affect Disord. 1998;50:187201.

11. Dell'Osso L, Pini S, Tundo A, Sarno N, Musetti L, Cassano GB. Clinical characteristics of mania, mixed mania, and bipolar depression with psychotic features. Compr Psychiatry. 2000;41:242-7.

12. Dias VV, Brissos S, Frey BN, Kapczinski F. Insight, quality of life and cognitive functioning in euthymic patients with bipolar disorder. J Affect Disord. 2008;110:75-83.

13. David A, Buchanan A, Reed A, Almeida O. The assessment of insight in psychosis. Br J Psychiatry. 1992;161:599-602.

14. Sturman ED, Sproule BA. Toward the development of a Mood Disorders Insight Scale: modification of Birchwood's Psychosis Insight Scale. J Affect Disord. 2003;77:21-30.

15. Beck AT, Baruch E, Balter JM, Steer RA, Warman DM. A new instrument for measuring insight: the Beck Cognitive Insight Scale. Schizophr Res. 2004;68:319-29.

16. Silva Rde A, Mograbi DC, Silveira LA, Nunes AL, Novis FD, Cavaco $\mathrm{PA}$, et al. Mood self-assessment in bipolar disorder: a comparison between patients in mania, depression, and euthymia. Trends Psychiatry Psychother. 2013;35:141-5.

17. de Assis da Silva R, Mograbi DC, Silveira LA, Nunes AL, Novis FD, Landeira-Fernandez $\mathrm{J}$, et al. The reliability of self-assessment of affective state in different phases of bipolar disorder. J Nerv Ment Dis. 2014;202:386-90.

18. Olaya B, Marsà F, Ochoa S, Balanzá-Martínez V, Barbeito S, García-Portilla MP, et al. Development of the Insight Scale for Affective Disorders (ISAD): modification from the Scale to Assess Unawareness. J Affect Disord. 2012;142:65-71.

19. American Psychiatric Association. Diagnostic and Statistical Manual of Mental Disorders, Fifth Edition (DSM-5). Arlington: American Psychiatric Publishing; 2013.

20. Spearing MK, Post RM, Leverich GS, Brandt D, Nolen W. Modification of the Clinical Global Impressions (CGI) Scale for use in bipolar illness (BP): the CGI-BP. Psychiatry Res. 1997;73:159-71.

21. de Assis da Silva R, Mograbi DC, Camelo EV, Morton GD, LandeiraFernandez J, Cheniaux E. Cross-cultural adaptation, validation and factor structure of the Insight Scale for Affective Disorders. J Affect Disord. 2015;178:181-7.

22. Bressi C, Porcellana M, Marinaccio PM, Nocito EP, Ciabatti M, Magri $L$, et al. The association between insight and symptoms in bipolar inpatients: an Italian prospective study. Eur Psychiatry. 2012;27:619-24.

23. Dell'Osso L, Pini S, Cassano GB, Mastrocinque C, Seckinger RA, Saettoni $M$, et al. Insight into illness in patients with mania, mixed mania, bipolar depression and major depression with psychotic features. Bipolar Disord. 2002;4:315-22.

24. Fennig S, Everett E, Bromet EJ, Jandorf L, Fennig SR, TenenbergKarant $M$, et al. Insight in first-admission psychotic patients. Schizophr Res. 1996;22:257-63.

25. Cheniaux E, Landeira-Fernandez J, Lessa Telles L, Lessa JL, Dias A, Duncan T, et al. Does schizoaffective disorder really exist? A systematic review of the studies that compared schizoaffective disorder with schizophrenia or mood disorders. J Affect Disord. 2008;106:209-17.

26. Camelo EVM, Velasques B, Ribeiro $P$, Netto $T$, Cheniaux $E$. Attention impairment in bipolar disorder: a systematic review. Psychol Neurosci. 2013;6:299-309.

27. Dias VV, Brissos S, Carita AI. Clinical and neurocognitive correlates of insight in patients with bipolar I disorder in remission. Acta Psychiatr Scand. 2008;117:28-34.

\section{Correspondence:}

Rafael de Assis da Silva

Rua Largo do Machado, 29/411, Catete

22221-020 - Rio de Janeiro, RJ - Brazil

E-mail: rafaelpsiq@gmail.com 